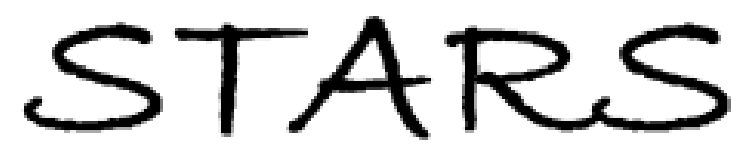

University of Central Florida

STARS

$1-1-2014$

\title{
Advances in quantitative nanoscale subsurface imaging by mode- synthesizing atomic force microscopy
}

\author{
P. Vitry \\ E. Bourillot \\ C. Plassard \\ Y. Lacroute \\ L. Tetard \\ University of Central Florida
}

See next page for additional authors

Find similar works at: https://stars.library.ucf.edu/facultybib2010

University of Central Florida Libraries http://library.ucf.edu

This Article is brought to you for free and open access by the Faculty Bibliography at STARS. It has been accepted for inclusion in Faculty Bibliography 2010 s by an authorized administrator of STARS. For more information, please contactSTARS@ucf.edu.

\section{Recommended Citation}

Vitry, P.; Bourillot, E.; Plassard, C.; Lacroute, Y.; Tetard, L.; and Lesniewska, E., "Advances in quantitative nanoscale subsurface imaging by mode-synthesizing atomic force microscopy" (2014). Faculty Bibliography 2010s. 6235.

https://stars.library.ucf.edu/facultybib2010/6235

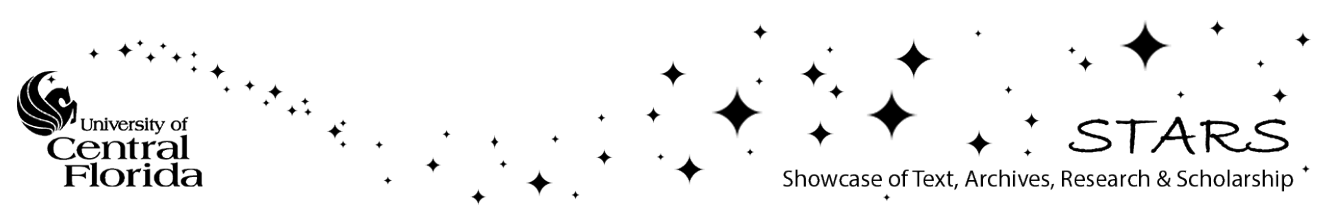




\section{Authors}

P. Vitry, E. Bourillot, C. Plassard, Y. Lacroute, L. Tetard, and E. Lesniewska 


\section{Advances in quantitative nanoscale subsurface imaging by mode-synthesizing atomic force microscopy}

Cite as: Appl. Phys. Lett. 105, 053110 (2014); https://doi.org/10.1063/1.4892467

Submitted: 15 January 2014 . Accepted: 22 July 2014 . Published Online: 07 August 2014

P. Vitry, E. Bourillot, C. Plassard, Y. Lacroute, L. Tetard, and E. Lesniewska
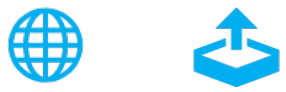

\section{ARTICLES YOU MAY BE INTERESTED IN}

Nanoscale subsurface imaging via resonant difference-frequency atomic force ultrasonic microscopy

Journal of Applied Physics 101, 114324 (2007); https://doi.org/10.1063/1.2743908

Sub-surface AFM imaging using tip generated stress and electric fields

Applied Physics Letters 110, 123108 (2017); https://doi.org/10.1063/1.4977837

Detection of subsurface cavity structures using contact-resonance atomic force microscopy Journal of Applied Physics 121, 154301 (2017); https://doi.org/10.1063/1.4981537

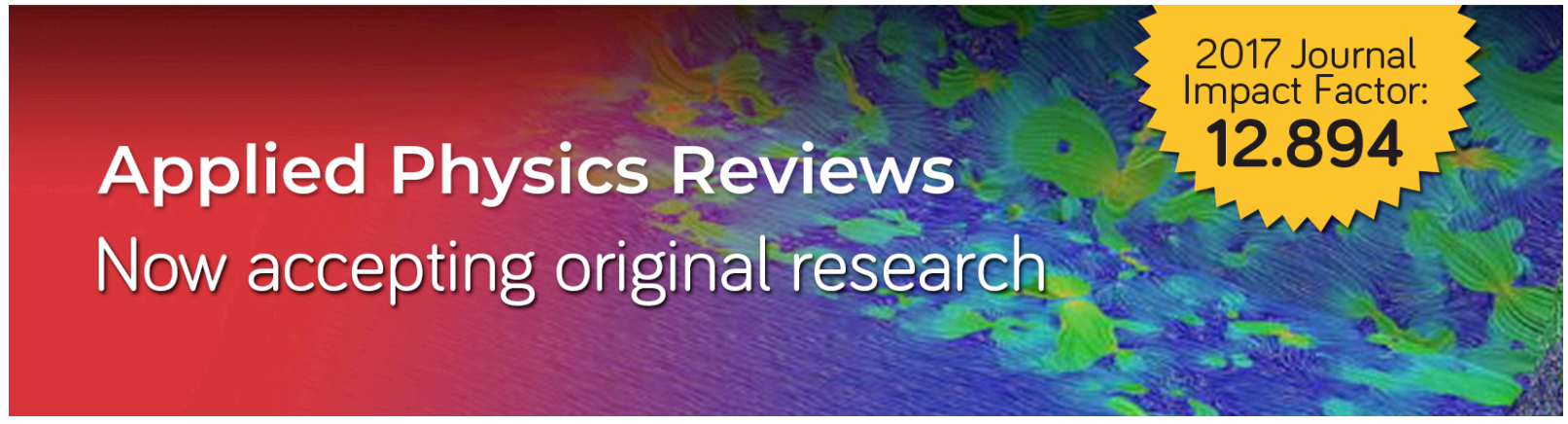




\title{
Advances in quantitative nanoscale subsurface imaging by mode-synthesizing atomic force microscopy
}

\author{
P. Vitry, ${ }^{1}$ E. Bourillot, ${ }^{1}$ C. Plassard,${ }^{1}$ Y. Lacroute,${ }^{1}$ L. Tetard,${ }^{2}$ and E. Lesniewska ${ }^{1}$ \\ ${ }^{1}$ ICB, UMR CNRS 6303 CNRS-University of Bourgogne, Dijon F-21078, France \\ ${ }^{2}$ Nanoscience Technology Center, University of Central Florida, Orlando, Florida 32826, USA
}

(Received 15 January 2014; accepted 22 July 2014; published online 7 August 2014)

\begin{abstract}
This paper reports on advances toward quantitative non-destructive nanoscale subsurface investigation of a nanofabricated sample based on mode synthesizing atomic force microscopy with heterodyne detection, addressing the need to correlate the role of actuation frequencies of the probe $f_{p}$ and the sample $\mathrm{f}_{\mathrm{s}}$ with depth resolution for $3 \mathrm{D}$ tomography reconstruction. Here, by developing a simple model and validating the approach experimentally through the study of the nanofabricated calibration depth samples consisting of buried metallic patterns, we demonstrate avenues for quantitative nanoscale subsurface imaging. Our findings enable the reconstruction of the sample depth profile and allow high fidelity resolution of the buried nanostructures. Non-destructive quantitative nanoscale subsurface imaging offers great promise in the study of the structures and properties of complex systems at the nanoscale. (C) 2014 AIP Publishing LLC.
\end{abstract}

[http://dx.doi.org/10.1063/1.4892467]

Atomic force microscopy (AFM) and associated techniques mostly provide surface properties, while the observation of sub-surface nanoscale defects remains a great challenge. ${ }^{1}$ The rising need for non-destructive methods to investigate materials subsurface properties led to the emergence of a variety of techniques ${ }^{2-5}$ including modesynthesizing $\mathrm{AFM}^{6}$ (MSAFM), enabling the detection of nanoscale structures buried under several hundreds of nanometers, well below the contact radius of the AFM tip. ${ }^{7-9}$ The operating principle of MSAFM is founded on the nonlinear mixing of two ultrasonic waves, one launched at the base of the AFM probe at frequency $f_{p}$ and a second one launched at the sample base at frequency $\mathrm{f}_{\mathrm{s}}$ (Refs. 10 and 11) (Fig. 1(a)). The mixing product generated as a result of the nonlinear tip-sample interaction thus contains subsurface information. ${ }^{12-17}$ However, the development of a theoretical model and the design of calibration samples for volume investigations remain quite challenging. $9,18,19$ Here, we study the impact of difference frequency $\Delta \mathrm{f}=\left|\mathrm{f}_{\mathrm{p}}-\mathrm{f}_{\mathrm{s}}\right|$ and ultrasonic frequency range on the investigation depth $\mathrm{z}_{\Delta \mathrm{f}}$ using a simple theoretical model and we verify the results experimentally.

To overcome the persistent lack $^{20}$ in thorough determination of the effect of $\Delta f$ on $z_{\Delta f}$, a predictive calculation based on the evaluation of the attenuation coefficients of the respective ultrasonic waves is established here to link $\mathrm{z}_{\Delta \mathrm{f}}$ with the applied frequencies $\left(\mathrm{f}_{\mathrm{s}}\right.$ and $\mathrm{f}_{\mathrm{p}}$ ) and $\Delta \mathrm{f}$. We consider two ultrasonic waves $S_{p}$ and $S_{s}$, launched at the base of the probe and the sample, respectively, and assume that their respective amplitudes $A_{p}$ and $A_{s}$ are attenuated, ${ }^{21}$ such that

$$
\begin{aligned}
& S_{p}(t)=A_{p} e^{-\frac{\alpha_{p} z}{v}} \cos \left(\omega_{p} t+\varphi_{p}\right), \\
& S_{s}(t)=A_{s} e^{-\frac{\alpha_{s} z}{v}} \cos \left(\omega_{s} t+\varphi_{s}\right),
\end{aligned}
$$

where $\alpha_{\mathrm{p}}$ and $\alpha_{\mathrm{s}}$ are the attenuation coefficients, and $\omega_{\mathrm{p}}=2 \pi \mathrm{f}_{\mathrm{p}}$ and $\omega_{\mathrm{s}}=2 \pi \mathrm{f}_{\mathrm{s}}$ are the frequencies of the respective waves. $v$ is the velocity of ultrasonic waves in the material (in our case, the velocity is considered the same for both waves). As reported by Verbiest et al. ${ }^{8}$ and Cantrell et al., ${ }^{9}$ the subsurface information is contained in the oscillation at the difference frequency $\Delta \mathrm{f}$. Hence, we focus here on the mixing product in the resulting signal detected $S$. Under the assumption that $A_{p}=A_{s}$ as the tip and the sample interact, $S$ is such that

$$
S=2 A(z) \cos \left(\Delta \omega t+\Delta \varphi_{a}\right) \cos \left(\Delta \Omega t+\Delta \varphi_{p}\right)
$$

with $\Delta \omega=\frac{\left|\omega_{s}-\omega_{p}\right|}{2}=2 \pi \frac{|f s-f p|}{2}=\pi \Delta f$ and $\Delta \Omega=\frac{\omega s+\omega p}{2}$, and the attenuation amplitude of the mixed wave $A(z)$ is

$$
A(z)=A_{0} e^{-\left(\frac{\left|\alpha_{p}-\alpha_{s}\right| z}{v}\right)} .
$$

In heterodyne detection, one only monitors the oscillation at $\Delta f$, so we simplify the expression

$$
S^{\prime}(t)=A(z) \cos \left(\Delta \omega t+\Delta \varphi_{a}\right)
$$

Equation (3) shows the role of the attenuation amplitude $A(z)$, which depends in turn on the attenuations coefficients $\alpha_{\mathrm{p}}$ and $\alpha_{\mathrm{s}}$ as shown in Eq. (2). Hence, $S^{\prime}(t)$ will be maximal when $A(z)$ is maximal, i.e., when $\left|\alpha_{p}-\alpha_{s}\right|$ reaches its minimum value. We have detected the changes in amplitude and phase of the oscillation at $\Delta \mathrm{f}$ and propose a relationship between $\Delta \mathrm{f}$ and $\mathrm{z}_{\Delta \mathrm{f}}$. The results are presented in Fig. 1 for a selected combination of parameters.

During its propagation in the material, the energy of ultrasonic waves is attenuated via various mechanisms. Overall, attenuation $A_{z}(d B)$ (which is related to $|A(z)|^{2}$ ) follows an exponential law that can be expressed in terms of intensity $I_{0}$ at the entrance of the material and the intensity $I_{z}$ at the depth $z: A_{z}(d B)=10 \log \left(I_{0} / I_{z}\right)$. Consequently, for a given material and a given ultrasonic frequency, the attenuation $A_{z}(d B)$ increases linearly with $\mathrm{z}_{\Delta \mathrm{f}}$ such that: $A_{z}(d B) \propto \alpha \mathrm{z}_{\Delta \mathrm{f}} \propto f z$, where $\alpha$ is the attenuation coefficient (in $\mathrm{dB} \cdot \mathrm{cm}^{-1}$ ), $f$ is the frequency (in $\mathrm{Hz}$ ), and $\mathrm{z}_{\Delta \mathrm{f}}$ (in $\mathrm{cm}$ ). 

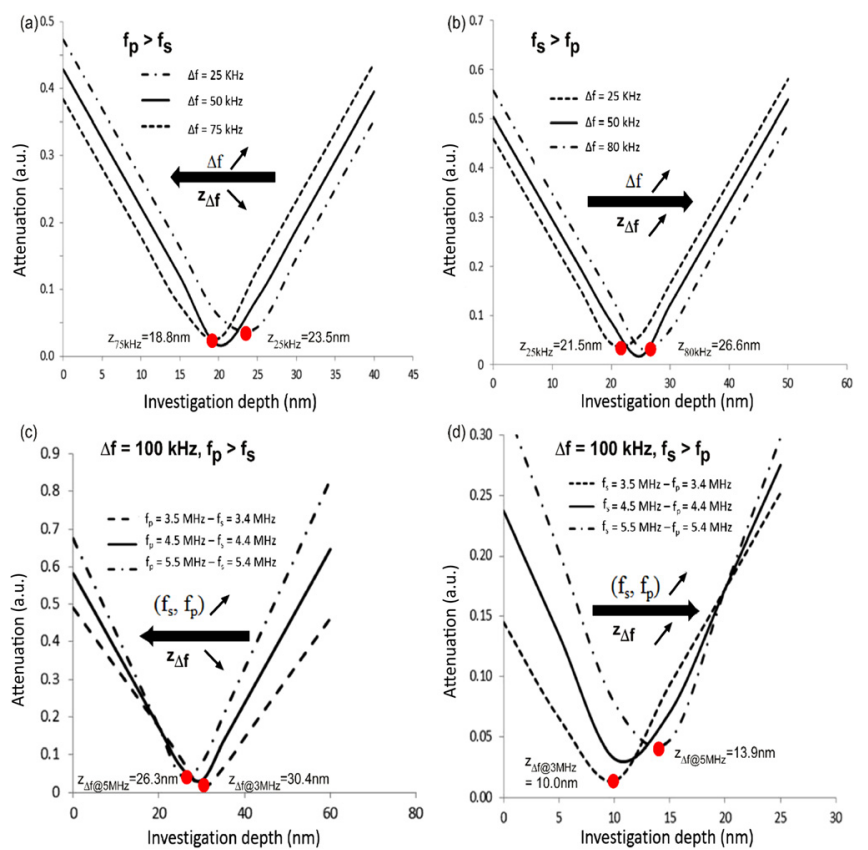

FIG. 1. Predicted evolution of the investigation depth $\mathrm{z}_{\Delta \mathrm{f}}$. (a) Evolution of the attenuation coefficient in case of $f_{s}<f_{p}$. The value of tip frequency $f_{p}$ was fixed at $4.500 \mathrm{MHz}$ while the sample frequency $\mathrm{f}_{\mathrm{s}}$ progressively decreased from 4.475 to $4.425 \mathrm{MHz}$. (b) Evolution of the attenuation coefficient in case $f_{s}>f_{p}$. The sample frequency was fixed at $f_{s}=4.500 \mathrm{MHz}$, while the tip frequency $\mathrm{f}_{\mathrm{p}}$ increased from $4.525 \mathrm{MHz}$ to $4.580 \mathrm{MHz}$. (c) Influence of change of frequency range on the investigation depth $\mathrm{z}_{\Delta \mathrm{f}}$ in case $\mathrm{f}_{\mathrm{s}}<\mathrm{f}_{\mathrm{p}}$ for a fixed $\Delta \mathrm{f}=100 \mathrm{kHz}$. (d) Influence of change of frequency range on the investigation depth $\mathrm{z}_{\Delta \mathrm{f}}$ in case $\mathrm{f}_{\mathrm{s}}>\mathrm{f}_{\mathrm{p}}$ for a fixed $\Delta \mathrm{f}=100 \mathrm{kHz}$.

In addition, the attenuation coefficient $\alpha$, expressed for each component $\alpha_{p}$ and $\alpha_{s}$, depends on the depth $\mathrm{z}_{\Delta \mathrm{f}}$ as follows:

$$
\alpha=e^{-\frac{f \cdot z_{\Delta f} \cdot \operatorname{Ln}(10) / 10}{V}} .
$$

Thus, calculating the minimum resulting from attenuation of the mixed waves is connected to the absolute value of the difference of the attenuation coefficients $\left|\alpha_{p}-\alpha_{s}\right|$. This coefficient is calculated for each $\Delta \mathrm{f}$ value under various sets of parameters (Fig. 1).

For example, if considering $\mathrm{f}_{\mathrm{p}}=4.500 \mathrm{MHz}$ and $\mathrm{f}_{\mathrm{s}}=4.450 \mathrm{MHz}$, i.e., a difference $\Delta \mathrm{f}=50 \mathrm{kHz}$ as depicted in Fig. 1(a) (solid curve), by plotting $A_{z}(d B)$ as a function of the investigation depth $\mathrm{z}_{\Delta \mathrm{f}}$, a minimum in attenuation can be observed at $\mathrm{z}_{\Delta \mathrm{f}}=20 \mathrm{~nm}$. This investigation depth $\mathrm{z}_{\Delta \mathrm{f}}$ can then be linked to the attenuation amplitude $A(z)$ according to Eq. (2).

We now explore how $\mathrm{z}_{\Delta \mathrm{f}}$ varies as a function of the difference frequency $\Delta \mathrm{f}$ under the $\mathrm{f}_{\mathrm{s}}<\mathrm{f}_{\mathrm{p}}$ or $\mathrm{f}_{\mathrm{s}}>\mathrm{f}_{\mathrm{p}}$ conditions (Figs. 1(a) and 1(b)).

Case of $f_{s}<f_{p}$ : The value of probe frequency $\mathrm{f}_{\mathrm{p}}$ was fixed at $4.500 \mathrm{MHz}$ and the sample frequency $\mathrm{f}_{\mathrm{s}}$ progressively decreased from 4.475 to $4.425 \mathrm{MHz}$. The numerical model applied in the case of decreasing values of $\mathrm{f}_{\mathrm{s}}$ highlights a shift of the minimum of absorption as a function of $\Delta$ f used (Fig. 1(a)). Note that for a fixed $f_{p}$, a decrease in $f_{s}$ corresponds to an increase of $\Delta \mathrm{f}$ from $25 \mathrm{kHz}$ to $75 \mathrm{kHz}$, respectively. We observed a shift of the minimum attenuation to lower depths during sample investigation.
Case of $f_{s}>f_{p}$ : The sample frequency was fixed at $\mathrm{f}_{\mathrm{s}}=4.500 \mathrm{MHz}$ while the probe frequency $\mathrm{f}_{\mathrm{p}}$ increased from $4.525 \mathrm{MHz}$ to $4.580 \mathrm{MHz}$. As can be seen in Fig. 1(b), an increase in difference frequency $\Delta \mathrm{f}$ leads to a shift of the minimum attenuation, in the direction of the greater investigation depths.

Furthermore, we considered the influence of the range of the frequency sets used in MSAFM on the investigation depth $\mathrm{z}_{\Delta \mathrm{f}}$. By maintaining $\Delta \mathrm{f}$ constant, the behavior of the attenuation coefficient is given from the curves in Figs. 1(c) and 1(d) as a function of $\mathrm{z}_{\Delta \mathrm{f}}$ for three different frequency ranges: $3 \mathrm{MHz}$ range, $4 \mathrm{MHz}$ range, and $5 \mathrm{MHz}$ range. For the two cases considered $f_{s}>f_{p}$ or $f_{s}<f_{p}, z_{\Delta f}$ appeared to change with the range of frequency used. Thus, our results show that the shift of the attenuation curve, and consequently $\mathrm{z}_{\Delta \mathrm{f}}$, depends not only on $\Delta \mathrm{f}$ but also on the range of the frequencies $f_{s}$ and $f_{p}$.

For experimental verification, we modified an AFM (Nanoscope IIIA controller, Bruker) (Fig. 2(a)) to host the piezoelectric crystals (PZT, Physik Instrument) required for MSAFM. Silicon nitride cantilevers (DNP-S, Bruker, $\mathrm{k}=0.12 \mathrm{~N} / \mathrm{m}$ ) were used. We estimated the contact radius of $30 \pm 10 \mathrm{~nm}$ after MS-AFM analysis on standard diamond calibration sample. Piezoelectric crystals were glued to the sample and cantilever, respectively, $f_{s}$ and $f_{p}$ were generated in the range from 3.0 to $5.0 \mathrm{MHz}$ through individual waveforms generators (Agilent 33220A) connected to the respective piezoelectric bimorph. The phase of the oscillation at
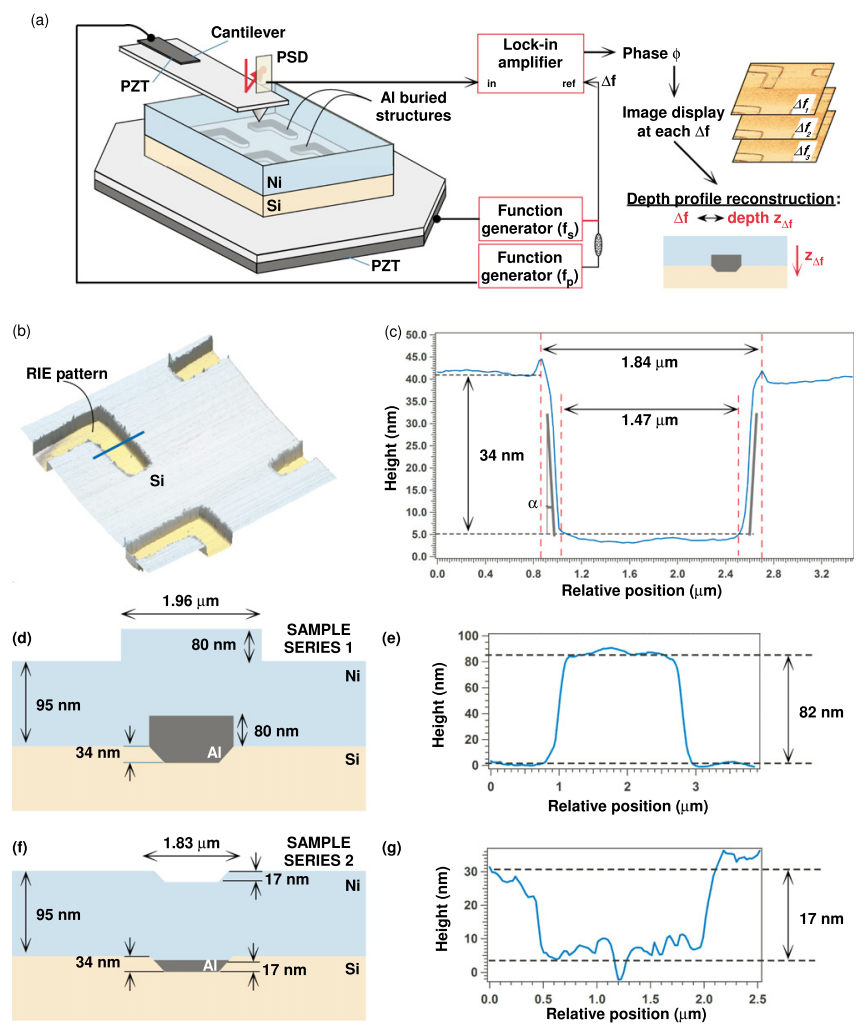

FIG. 2. Calibration samples developed for quantitative nanoscale subsurface imaging with MSAFM. (a) Experimental setup of MSAFM. (b) Topographical AFM image after reactive ion etching. (c) Cross section extracted at selected blue line in (b). (d) Schematic of the design of sample 1. (e) Profile representative of the topography of pattern contained in sample 1. (f) Schematic of the design of sample 2. (g) Profile representative of the topography of sample 2 . 
the difference frequency $\Delta \mathrm{f}$ was monitored via a lock-in amplifier (Lock-In Amplifier SRS 844, Stanford Research) using the AFM position sensitive detector (PSD) signal $\mathrm{S}(\mathrm{t})$ as an input and the predicted $\Delta \mathrm{f}$ as reference (see schematics in Fig. 2(a)). The phase response of the oscillation was sent to the AFM controller to display the image. After acquiring a sequence of images at various $\Delta \mathrm{f}$ (as shown in Fig. 3), the corresponding depth information could be extracted from Fig. 1 for each image to reconstruct a depth profile of each sample presented in Fig. 4.

To that end, two sets of calibration samples with buried metallic patterns were fabricated by nanolithography using electron-beam lithography (e-Line ${ }^{\text {Plus }}$, Raith) on a layer of $300 \mathrm{~nm}$ thick electro-sensitive polymer poly(methyl methacrylate) (PMMA) deposited on a silicon substrate. Reactive ion etching (RIE) was performed to etch the design patterns into the Si substrate. The patterned silicon surface was controlled by AFM to determine the etch depth in silicon $(34 \pm 2 \mathrm{~nm})$ and the angle edge $\alpha\left(79 \pm 1^{\circ}\right)$ (Fig. 2(c)).

The calibration samples thus consist of buried aluminum (Al) structures covered by a nickel (Ni) layer (Fig. 2). In the first set of samples (Fig. 2(d)), the Al structures were $114 \pm 2 \mathrm{~nm}$ in height, covered by $95 \pm 2 \mathrm{~nm}$ thickness of $\mathrm{Ni}$. The cross section of the pattern (Fig. 2(b)) reveals a height difference of $80 \mathrm{~nm}$ resulting from the mismatch between the thicknesses of $\mathrm{Al}$ deposited and the initial depth etched in the silicon substrate (Fig. 2(e)). The second set of samples (Fig. 2(f)) was obtained by deposition of a $17 \pm 1 \mathrm{~nm} \mathrm{Al}$ layer and coating with a $95 \pm 2 \mathrm{~nm}$ Ni layer. The pattern exhibited dips of $17 \pm 1 \mathrm{~nm}$ on the surface (Fig. $2(\mathrm{~g})$ ). In addition, the width of the surface features after Ni deposition was measured by AFM as indicated in Fig. 2.
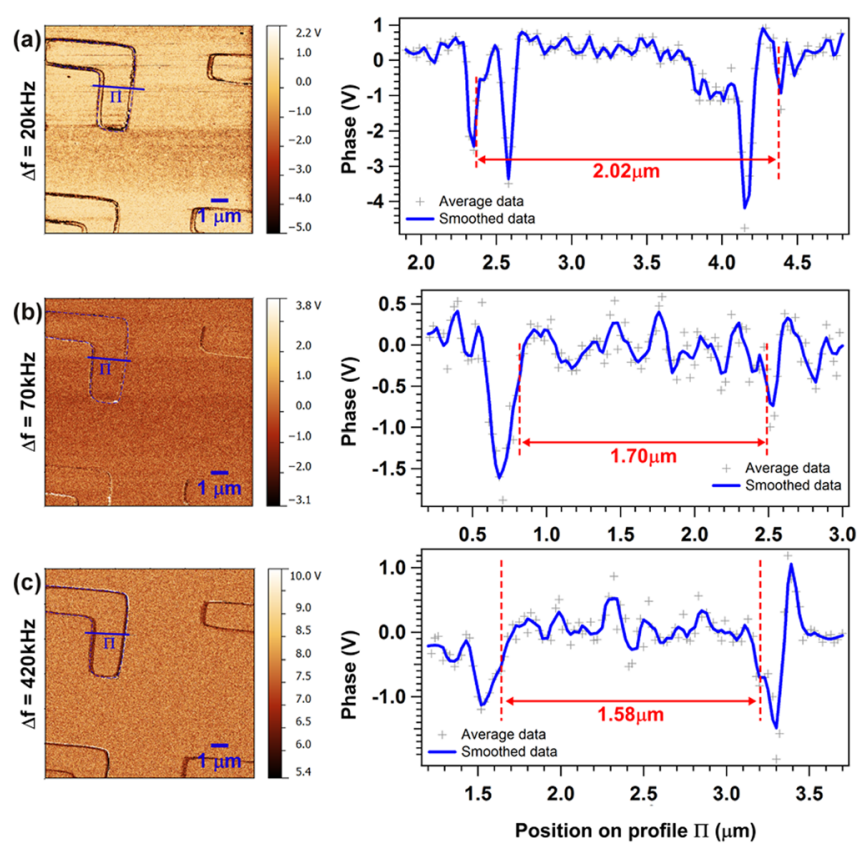

FIG. 3. MSAFM phase images at various $\Delta \mathrm{f}$ frequencies (Scan size $10 \mu \mathrm{m}$ acquired at scan rate of $0.5 \mathrm{~Hz}$ ). (a) $\Delta \mathrm{f}=20 \mathrm{kHz}$-width extracted at the section $\Pi: 2.02 \mu \mathrm{m}$. (b) $\Delta \mathrm{f}=70 \mathrm{kHz}$ - width extracted at the section $\Pi$ : $1.70 \mu \mathrm{m}$. (c) $\Delta \mathrm{f}=420 \mathrm{kHz}$ - width extracted at the section $\Pi: 1.58 \mu \mathrm{m}$. Phase was measured in a specified range $( \pm 10 \mathrm{~V})$ corresponding to a range in degrees of $\left( \pm 180^{\circ}\right)$.
To determine the relevance of the numerical model in the study of buried samples, we compared the results presented in Fig. 1 with experimental results obtained on the calibrated samples described in Fig. 2, using the same parameter as those considered for the numerical study. All driving amplitudes were fixed at $A_{p}=A_{s}=4 \mathrm{~V}_{\mathrm{pp}}$. MSAFM phase images were acquired for a set of frequencies from 20 $\mathrm{kHz}$ to $420 \mathrm{kHz}$ at each step of $10 \mathrm{kHz}$. The results are presented in Figs. 3 and 4. Note that the set of frequencies selected to acquire the images presented here did not coincide with the natural resonances of the cantilever.

To investigate sample $1, \mathrm{f}_{\mathrm{s}}$ was fixed at $4.300 \mathrm{MHz}$ and $\Delta f$ was increased by decreasing $f_{p}$, while maintaining $f_{p}<f_{s}$. The MSAFM phase images were obtained at incremental frequencies of $10 \mathrm{kHz}$ starting at $\Delta \mathrm{f}=20 \mathrm{kHz}$. Three images obtained during this sequence are depicted in Fig. 3. We observed that the contour of the buried pattern (highlighted by the dashed blue line in the MSAFM images in Fig. 3) appeared clearly in the images due to changes at the interface and exhibits different dimensions at each step. A crosssection was extracted for each image (right column in Fig. 3) and a variation in the width of the pattern with respect to $\Delta f$ was observed. In the case of $f_{s}>f_{p}$, the width decreased when $\Delta \mathrm{f}$ increased (Figs. 3(b) and 3(c)). In order to correlate the width values extracted from each MSAFM phase image with the investigation depth $\mathrm{z}_{\Delta \mathrm{f}}$, the frequency values were applied to the numerical model discussed in Fig. 1. Consequently, we found that successive $\Delta \mathrm{f}$ steps of $10 \mathrm{kHz}$ correspond to a nearly linear variation of $\mathrm{z}_{\Delta \mathrm{f}}$ (Fig. 4(a)). By combining the width of the buried structures extracted from the cross-sections of the MSAFM phase images (Fig. 3) and the investigation depth $\mathrm{z}_{\Delta \mathrm{f}}$ determined for each $\Delta \mathrm{f}$ using the numerical model (Fig. 1), we could reconstruct the depth profile characteristic to the sample. For sample set 1, in the region around the $\mathrm{Ni} / \mathrm{Si}$ interface, the reconstructed depth composition is presented in Fig. 4(c) (region probed indicated in the inset). Note that the depth scale (z axis) is not respected on the graph. Line 2 (red dashed line) in Fig. 4(c) indicates the $\mathrm{Si} / \mathrm{Ni}$ interface and was probed with $\Delta \mathrm{f}=70 \mathrm{kHz}$. Overall, the experimental results used to reconstruct the pattern profile agree well with the tapered angle resulting from the RIE etch as the decrease close to $80 \%$ in the width of the pattern could be measured between the frame acquired at $\Delta \mathrm{f}=20 \mathrm{kHz}$ (Fig. 3(a), close to the top of the $\mathrm{Al}$ structure) and the frame acquired at $\Delta \mathrm{f}=420 \mathrm{kHz}$ (Fig. 3(c), close to the bottom of the Al structure). This is identical to the width decrease of the pattern described in Fig. 2(c). In addition, the etched depth obtained from the reconstruction using the numerical model is equal to $31 \pm 2 \mathrm{~nm}$ (in the Si layer in Fig. 4(c)), which is in agreement with the AFM profile in Fig. 2(d) $(34 \pm 2 \mathrm{~nm})$. Hence, the angle $\alpha$ of the slope between the points 2 and 3 in Fig. 4(c) was estimated at $79 \pm 2^{\circ}$, in perfect agreement with the $79 \pm 1^{\circ}$ measured experimentally on 10 different samples as discussed in Fig. 2. Overall, these results are in good agreement with the profile of sample calibration.

The experiment was repeated in the case $f_{s}<f_{p}$ with a fixed $f_{p}$ equal to $4.300 \mathrm{MHz}$. The profile of the pattern is obtained following the same protocol (Figs. 4(b) and 4(d)). The reconstructed depth composition is presented in 

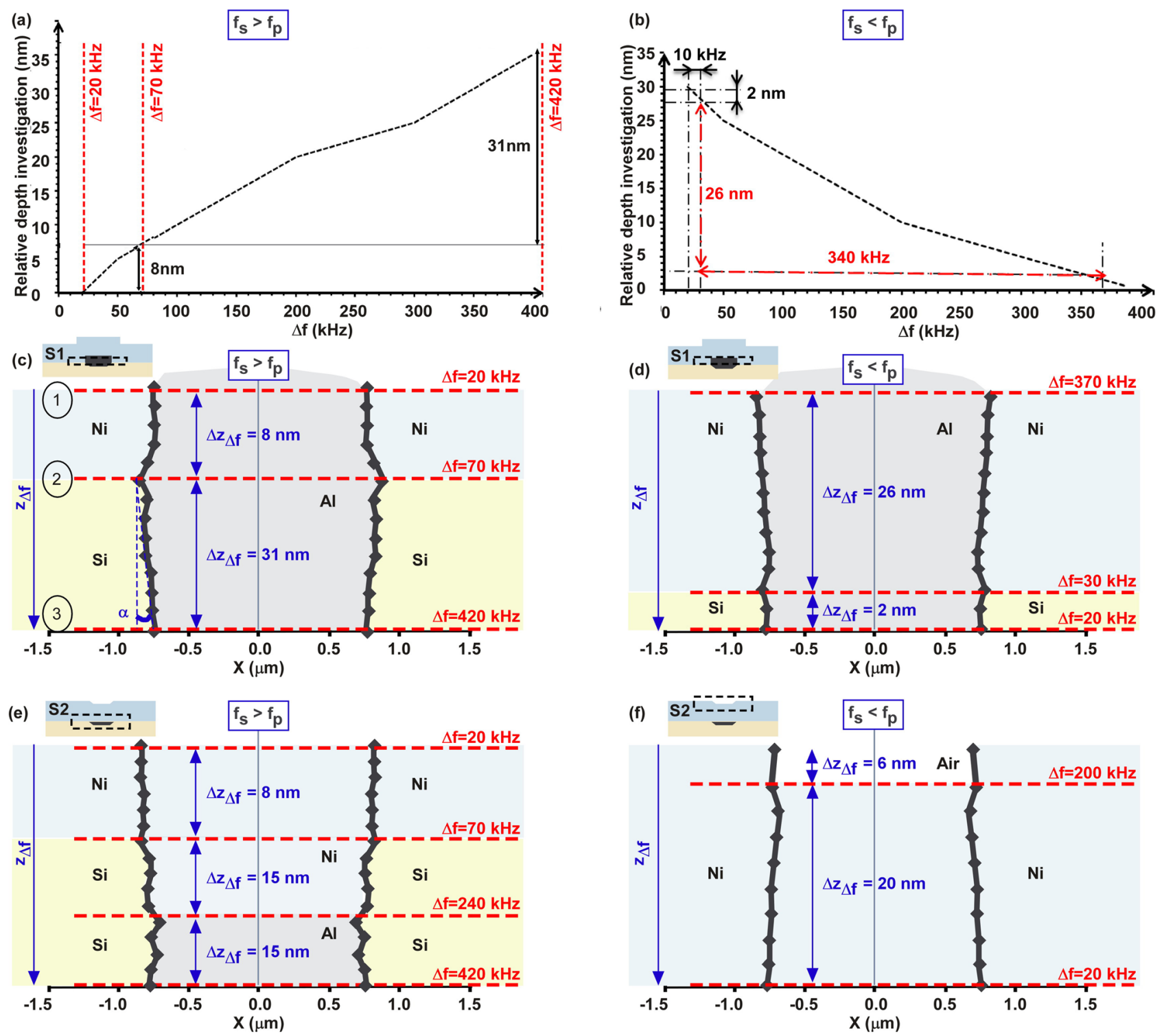

FIG. 4. Subsurface composition reconstructions of calibration samples 1 and 2 based on MSAFM measurements and numerical model. (a) Representation of the dependence of relative depth investigation as a function of $\Delta f$ in the case $f_{s}>f_{p}$ with fixed $f_{s}=4.300 \mathrm{MHz}$. (b) Representation of the dependence of relative depth investigation as a function of $\Delta \mathrm{f}$ in case $\mathrm{f}_{\mathrm{s}}<\mathrm{f}_{\mathrm{p}}$ with fixed $\mathrm{f}_{\mathrm{p}}=4.300 \mathrm{MHz}$. (c) Reconstruction of the depth composition of sample 1 pattern (area depicted in the inset) in the case $f_{s}>f_{p}$ based on the compilation of MSAFM data with fixed $f_{s}=4.300 \mathrm{MHz}$. The depth was extracted from the curve in (a) as indicated by the markers of $\Delta \mathrm{f}$ and relative difference in height. (d) Reconstruction of the depth composition of sample 1 pattern (area depicted in the inset) in case $\mathrm{f}_{\mathrm{s}}<\mathrm{f}_{\mathrm{p}}$ based on the compilation of MSAFM data with fixed $\mathrm{f}_{\mathrm{p}}=4.300 \mathrm{MHz}$. The depth was extracted from the curve in (b) as indicated by the markers of $\Delta \mathrm{f}$ and relative difference in height. (e) Reconstruction of the depth composition of sample 2 (area depicted in the inset) profile pattern in case $f_{s}>f_{p}$ based on the compilation of MSAFM data with $\left(\mathrm{f}_{\mathrm{s}}, \mathrm{f}_{\mathrm{p}}\right)$ in the $4 \mathrm{MHz}$ range. (f) Reconstruction of the depth composition of sample 2 profile (area depicted in the inset) pattern in case $\mathrm{f}_{\mathrm{s}}<\mathrm{f}_{\mathrm{p}}$ based on the compilation of MSAFM data with $\left(\mathrm{f}_{\mathrm{s}}, \mathrm{f}_{\mathrm{p}}\right)$ in the $3 \mathrm{MHz}$ range.

Fig. 4(d) (region probed indicated in the inset). Under these conditions, the volume of the sample probed at $\Delta \mathrm{f}=370 \mathrm{kHz}$ is closer to the surface than the plane probed at $\Delta \mathrm{f}=370 \mathrm{kHz}$. We could find the boundary delimitation Si$\mathrm{Ni}$ (dotted line) at $\Delta \mathrm{f}=30 \mathrm{kHz}$. Again, a good correlation between the profile and the numerical model was found.

The same study was performed on sample 2 described in Fig. 2(f). The two cases $f_{s}>f_{p}$ (with $f_{s}$ fixed at $4.3 \mathrm{MHz}$ ) and $\mathrm{f}_{\mathrm{s}}<\mathrm{f}_{\mathrm{p}}$ (with $\mathrm{f}_{\mathrm{p}}$ fixed at $3.6 \mathrm{MHz}$ ) have been studied and the results are presented in Figs. 4(e) and 4(f), respectively. The reconstruction is in good agreement with AFM measurements presented in Fig. 2. Finally, the frequency range was shifted to the $3 \mathrm{MHz}$ range. The results (Fig. 4(f)) show that the variation in the depth investigation has been modified, in accordance with the numerical model results (Fig. 1(c)). In this case, the investigation occurs closer to the surface of the sample (see region probed in the inset). The depth investigation variation evolution is represented in Fig. 4(b).

We observed that on both samples, for the same range of frequency and when $f_{s}>f_{p}$ (Figs. 4(c) and 4(e)), the investigation depth is equivalent ( $39 \mathrm{~nm}$ for sample \#1 and $38 \mathrm{~nm}$ for sample \#2). The MSAFM phase images revealed the same etching area in silicon with $\mathrm{Al}$ depositing. On the other hand, when probing with $\mathrm{f}_{\mathrm{s}}<\mathrm{f}_{\mathrm{p}}$ using a $3 \mathrm{MHz}$ range for frequency $\left(\mathrm{f}_{\mathrm{s}}, \mathrm{f}_{\mathrm{p}}\right)$ (Fig. 4(f)), while maintaining the same $\Delta \mathrm{f}$ as in Fig. 4(d), the same range of investigation depth $\mathrm{z}_{\Delta \mathrm{f}}$ could be spanned but closer to the surface. In accordance with the numerical prediction, when $\left(f_{s}, f_{p}\right)$ is in a lower range of 
frequency, MSAFM inspects a smaller depth of the sample, which explains the transition zone air-nickel on the graph of sample 2 (Fig. 4(f)).

In summary, we unveiled the influence of the range of frequencies used $\left(f_{s}, f_{p}\right)$ and the frequencies variation $(\Delta f)$, on the investigation depth $\mathrm{z}_{\Delta \mathrm{f}}$ of the sample with MSAFM. The numerical study was validated experimentally on metallic calibration samples with buried patterns. Therefore, the proposed simple model constitutes a substantial progress toward quantitative subsurface studies. The different interfaces of materials could be identified allowing the depth profile reconstruction of the sample. Importantly, the phase images were not related to the sample's topography. Finally, we evaluated the investigation depth sensitivity in MSAFM by monitoring of subsurface defect propagation. Overall, MSAFM emerges as a very powerful tool for the nondestructive control allowing the $3 \mathrm{D}$ reconstruction of an object comprising buried objects with high spatial resolution (lateral resolution and depth resolution).

We acknowledge the financial support of Region Bourgogne Council, Institute Carnot ARTS and Labex Action Integrated Smart System programs.

${ }^{1}$ N. A. Burnham, A. J. Kulik, G. Gremaud, P. J. Gallo, and F. Oulevey, J. Vac. Sci. Technol. B 14(2), 794-799 (1996).

${ }^{2}$ C. Plassard, E. Bourillot, J. Rossignol, Y. Lacroute, E. Lepleux, L. Pacheco, and E. Lesniewska, Phys. Rev. B 83(12), 121409 (2011).
${ }^{3}$ J. H. Lee and Y. B. Gianchandani, Rev. Sci. Instrum. 75, 1222 (2004).

${ }^{4}$ G. Shekhawat and V. P. Dravid, Science 310(5745), 89 (2005).

${ }^{5}$ L. Tetard, A. Passian, K. T. Venmar, R. M. Lynch, B. Voy, G. Shekhawat, V. P. Dravid, and T. Thundat, Nat. Nanotechnol. 3(8), 501 (2008).

${ }^{6}$ A. Passian, T. Thundat, and L. Tetard, U.S. patent application 12/726,083 (2013).

${ }^{7}$ G. S. Shekhawat, S. Avasthy, A. K. Srivastava, S. H. Tark, and V. P. Dravid, IEEE Trans. Nanotechnol. 9(6), 671-674 (2010).

${ }^{8}$ G. J. Verbiest, T. H. Oosterkamp, and M. J. Rost, Nanotechnology 24(36), 365701 (2013).

${ }^{9}$ S. A. Cantrell, J. H. Cantrell, and P. T. Lillehei, J. Appl. Phys. 101(11), 114324 (2007).

${ }^{10}$ T. Fukuma, K. Kimura, K. Kobayashi, K. Matsushige, and H. Yamada, Rev Sci. Instrum. 76, 126110 (2005).

${ }^{11}$ O. V. Kolosov, M. R. Castell, C. D. Marsh, G. A. D. Briggs, T. I. Kamins, and R. S. Williams, Phys. Rev. Lett. 81(5), 1046 (1998).

${ }^{12}$ U. Rabe, K. Janser, and W. Arnold, Rev. Sci. Instrum. 67(9), 3281-3293 (1996).

${ }^{13}$ K. B. Crozier, G. G. Yaralioglu, F. L. Degertekin, J. D. Adams, S. C. Minne, and C. F. Quate, Appl. Phys. Lett. 76(14), 1950-1952 (2000).

${ }^{14}$ M. T. Cuberes, H. E. Assender, G. A. D. Briggs, and O. Kolosov, J. Phys. D. Appl. Phys. 33, 2347 (2000).

${ }^{15}$ M. T. Cuberes, G. A. D. Briggs, and O. Kolosov, Nanotechnology 12(1), $53(2001)$

${ }^{16} \mathrm{M}$. T. Cuberes, B. Stegemann, B. Kaiser, and K. Rademann, Ultramicroscopy 107(10), 1053 (2007).

${ }^{17}$ L. Tetard, A. Passian, R. M. Lynch, B. H. Voy, G. Shekhawat, V. P. Dravid, and T. Thundat, Appl. Phys. Lett. 93, 133113 (2008).

${ }^{18}$ G. J. Verbiest, J. N. Simon, T. H. Oosterkamp, and M. J. Rost., Nanotechnology 23(14), 145704 (2012).

${ }^{19}$ G. Shekhawat and V. P. Dravid, Appl. Phys. Lett. 95(26), 263101 (2009).

${ }^{20}$ L. Tetard, A. Passian, R. H. Farahi, B. H. Voy, and T. Thundat, Methods Mol. Biol. 926, 331 (2012).

${ }^{21}$ J. L. Rose and P. B. Nagy, J. Acoust. Soc. Am. 107, 1807 (2000). 